\title{
Kronik Miyeloproliferatif Hastalık Olgularında JAK2 V617F Mutasyon Sıkığı
}

\section{The Frequency of JAK2 V617F Mutation in Patients with Chronic Myeloproliferative Disease}

\author{
Özlem ÖZ 1
}

1Harran Üniversitesi Tıp Fakültesi, Tıbbi Genetik Anabilim Dalı, Şanlıurfa, Türkiye

Öz.

Amaç: Kronik miyeloproliferatif hastalıklar kan hücre serilerinin aşıı proliferasyonu ile karakterize olup bu hastalıklardan sıklıkla görülen polisitemiavera (PV), esansiyeltrombositemi (ET) ve primermiyelofibrozis (PMF) genellikle JAK2 (Januskinaz 2), CALR (calreticulin) ve MPL (myeloproliferativeleukemia) genlerinde spesifik somatik mutasyonlar sonucu ortaya çıkmaktadır. Bu çalışmada polisitemi nedeniyle genetik polikliniğine başvuran PV, ET ve PMF hastalarında JAK2 V617F mutasyon sıkığının hastalık gruplarına göre tespiti ve elde edilen bu sonuçların literatür verileri ile karşılaştırıması amaçlanmıştır.

Materyal ve Metod: Şubat 2017-Şubat 2019 tarihleri arasında polisitemi nedeniyle başvuran ve JAK2 V617F mutasyon analizi yapılan 267 hastanın laboratuvar sonuçları retrospektif olarak incelendi. Hastalar PV, ET ve PMF tanısı alanlar olmak üzere 3 gruba ayrıldı. Her grupta JAK2 V617F mutasyon sıklığı ve hastaların demografik verileri kaydedildi.

Bulgular: Calıșmaya alınan toplam 267 hastanın 235'inde (\%88) PV, 31'inde (\%11,6) ET ve 1 hastada (\%0,4) PMF tanıI vardı. JAK2 V617F mutasyon pozitifliği PV hasta grubunun $\% 8,5$ 'nde, ET hasta grubunun $\% 9,7$ 'sinde saptandı. JAK2 V617F mutasyonu gözlenme durumu kökenlere göre karşılaştırıldığında Suriye'li hastalarda Türk hastalara kıyasla anlamlı olarak daha yüksekti $(p<0.05)$.

Sonuç: Bizim çalışmamızda Türk ve Suriye vatandaşları arasında JAK2 V617F mutasyonu açısından anlamlı farklılık tespit edildi. Bu durum JAK2 V617F mutasyonunun kökenlere göre farklıık gösterebileceğini göstermektedir. Ayrıca bu çalışma Şanlıurfa ilinde JAK2 V617F mutasyon sıklı̆ının değerlendirildiği ilk çalışma olması nedeniyle önem arz etmektedir.

Anahtar kelimeler: JAK2 V617F mutasyonu, Polisitemi, Polistemiavera, Esansiyeltrombositemi, Primermiyelofibrozis

Abstract

Background: Chronic myeloproliferative diseases are characterized by excessive proliferation of blood cell lines, the most common of which are polycythemia vera (PV), essential thrombocythemia (ET) and primary myelofibrosis (PMF), usually JAK2 (Janus kinase 2), CALR (calreticulin) and MPL (myeloproliferative leukemia) genes occur as a result of specific somatic mutations. The aim of this study was to determine the frequency of JAK2 V617F mutation in PV, ET and PMF patients who applied to the genetic polyclinic due to polycythemia and to compare these results with the literature data.

Materials and Methods: The laboratory results of 267 patients who presented with polycythemia between February 2017-February 2019 and tested JAK2 V617F mutation analysis were retrospectively reviewed. The patients were divided into three groups as PV, ET and PMF. The frequency of JAK2 V617F mutation and demographic data were recorded in each group.

Results: Of 267 patients included in the study, 235 (88\%) had PV, 31 (11.6\%) had ET and $1(0.4 \%)$ had PMF. JAK2 V617F mutation positivity was detected in $8.5 \%$ of PV patients and $9.7 \%$ of ET patients. The JAK2 V617F mutation was significantly higher in Syrian patients than in Turkish patients when compared to those of origin $(p<0.05)$.

Conclusions: In this study, a significant difference was found between Turkish and Syrian citizens in terms of JAK2 V617F mutation. This suggests that the JAK2 V617F mutation may differ by origin. In addition, this study is important because it is the first study to evaluate the frequency of JAK2 V617F mutation in Şanlıurfa.

Key words: JAK2 V617F mutation, Polycythemia, Polycythemia vera, Essential thrombocythemia, Primary myelofibrosis

\section{Sorumlu Yazar I \\ Corresponding Author}

\section{Dr. Özlem Öz}

Harran Üniversitesi Tıp Fakültesi Araştırma ve Uygulama Hastanesi Tıbbi Genetik ABD,

Osmanbey Kampüsü 63300 Haliliye/Şanlıurfa

e-mail: ozlemdroz1@gmail.com

Tel: +905054062262

Fax: +90 (414) 3183209

Geliş tarihi / Received: 15.11.2019

Kabul tarihi / Accepted: 03.12.2019

DOI: $10.35440 /$ hutfd.645383 


\section{Giriş}

Kronik miyeloproliferatif hastalıklar, kemik iliğinde klonal hematopoez ve hiperproliferasyon ile karakterize, bir veya daha fazla miyeloid seride aşırı miktarda olgun hücreye yol açan heterojen bir hematolojik malignite grubudur (1). Kronik miyeloproliferatif hastalıklar içerisinde yer alan polisitemia vera (PV), esansiyel trombositemi $(E T)$ ve primer miyelofibrozis (PMF) kan hücre serisinin aşırı proliferasyonu sonucu ortaya çıkmaktadır. Bu hastalıklar genellikle JAK2 (Janus kinaz 2), CALR (calreticulin) veya MPL (myeloproliferative leukemia) genlerindeki spesifik somatik mutasyonlarla karakterizedir. Kronik miyeloproliferatif hastalıklarda görülen ve hastalığın yaygın moleküler mekanizmaları arasında; JAK2 genindeki V617F mutasyonu, CALR geninin ekson 9'undaki mutasyonlar, trombopoietin reseptörünü kodlayan MPL geninin ekson 10'undaki mutasyonlar ve JAK2 geninin ekson 12'sindeki mutasyonlar yer alır. Bu mutasyonlar hastalığın tanısında önemli yer tutar ve tanı kriterleri olarak kabul edilir (2).

9. kromozomun kısa kolunda yer alan JAK2 geni, çok sayıda hematopoietik büyüme faktörü reseptörlerinin sinyal iletiminde anahtar rol oynayan bir sitoplazmik tirozin kinaz ailesinin bir üyesidir (3). Illk olarak 2005 yılında birbirinden bağımsız olarak dört farklı grup araştırmacı tarafindan JAK2 kinaz geninin 617. kodonunda (V617F) valin-fenilalanin dönüşümüne neden olan somatik mutasyon tanımlanmışır. Bu değişim kinaz domainini negatif regüle ederek Epo reseptör sinyalizasyonunda rol alan JAK-STAT ve diğer yolakların sitokinden bağımsız aktivasyonuna yol açar. JAK2 V617F mutasyonu, kronik miyeloproliferatif hastalıklarda sıklıkla tespit edilmektedir. Bu mutasyon PV'li hemen hemen her hastanın miyeloid hücrelerinde bulunurken, ET veya PMF'li hastaların ise yaklaşık yarısında gözlenir $(4,5)$.

Bu çalışmada, polisitemi nedeniyle genetik polikliniğine başvuran hastaların JAK2 V617F mutasyon sıklığının tespiti ve elde edilen bu sonuçların literatür verileri ile karşılaştıııması amaçlanmıştır. Çalışmamızın, bölgemizde bu konuda yapılan ilk araştırma olması nedeniyle literatüre katkı sağlayacağı düşünülmektedir.

\section{Materyal ve Metod}

Şubat 2017-Şubat 2019 tarihleri arasında polisitemi nedeniyle başvuran ve JAK2 V617F mutasyon analizi yapılan 267 hastanın laboratuvar sonuçları geriye dönük olarak incelendi.

$\mathrm{Bu}$ çalışma için Harran Üniversitesi Klinik Araştırmalar Etik Kurulu'ndan kurul izni alındı. Çalışmaya dahil edilen hastalar tanılara göre gruplara ayrıldı. Hastaların demografik verileri, JAK2 V617F mutasyonu taşıma durumları kaydedildi. Verilerin değerlendirilmesinde Statistical Package for the Social Sciences (SPSS, version 15.0, Chicago, IL, USA) istatistik programı kullanıldı. Hastaların demografik ve hatalıkla ilgili verilerinden rakamsal olanlar ortalama \pm standart sapma, kategorik olanlar yüzde oran şeklinde ifade edildi. Gruplar arasında $p<0.05$ değeri tespit edilenler anlamlı olarak kabul edildi.

\section{Bulgular}

Çalışmaya alınan 267 hastanın 235 (\%88)'inde PV, 31 $(\% 11,6)$ 'inde ET ve $1(\% 0,4)$ tanesinde PMF tanısı vardı. Hastaların 215 (\%80)'i erkek, 52 (\%20)'si kadındı. Çalışmadaki hastaların yaş ortalaması $42.18 \pm 15.55$ idi. Tablo 1 'de hastaların yaş, cinsiyet, ırk açısından demografik özelliklerine göre JAK2 V617F mutasyon durumu belirtildi. Toplam 267 hastanın 23'ünde JAK2 V617F mutasyonu pozitif saptanırken, 244'ünde JAK2 V617F mutasyonunun negatif olduğu tespit edildi. Hastalar kökenlerine göre kategorize edildiğinde; toplam 252 Türk hastanın 17 $(\% 6,7)$ 'sinde pozitif saptanırken, 15 Suriye'li hastanın 6 (\%40)'sında pozitif olduğu gözlendi. JAK2 V617F mutasyonu pozitiflik durumu kökenlere göre Pearson kikare testi ile karşılaştırıldığında Suriye'li hastalarda Türk hastalara kıyasla anlamlı olarak daha yüksekti $(p<0.05)$. Diğer parametreler açısından gruplar arasında anlamlı farklılık gözlenmedi (Tablo 1).

Tablo 1. JAK2 V617F mutasyonuna göre hastaların demografik özellikleri

\begin{tabular}{|c|c|c|c|c|c|}
\hline & & $\begin{array}{l}\text { JAK2 } \\
\text { V617F(+) }\end{array}$ & JAK2 V617F(-) & Toplam & $p$ \\
\hline 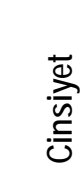 & $\begin{array}{l}\text { Erkek } \\
\mathrm{n}(\%) \\
\text { Kadın } \\
\mathrm{n}(\%)\end{array}$ & $\begin{array}{l}18 \\
(\% 8,4) \\
5 \\
(\% 9,6)\end{array}$ & $\begin{array}{l}197 \\
(\% 91,6) \\
47 \\
(\% 90,4)\end{array}$ & $\begin{array}{l}215 \\
(\% 100) \\
52 \\
(\% 100)\end{array}$ & 0,476 \\
\hline \multicolumn{2}{|c|}{ 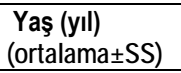 } & $50,95 \pm 16,78$ & $41,40 \pm 15,09$ & \multicolumn{2}{|l|}{$42,07 \pm 15,61$} \\
\hline \multirow{2}{*}{$\frac{\text { 엄 }}{\frac{y}{0}}$} & $\begin{array}{l}\text { Türk } \\
\text { n(\%) }\end{array}$ & $\begin{array}{l}17 \\
(\% 6,7)\end{array}$ & $\begin{array}{l}235 \\
(\% 93,3)\end{array}$ & $\begin{array}{l}252 \\
(\% 100)\end{array}$ & \multirow[b]{2}{*}{0,001} \\
\hline & $\begin{array}{l}\text { Suriye } \\
n(\%)\end{array}$ & $\begin{array}{l}6 \\
(\% 40)\end{array}$ & $\begin{array}{l}9 \\
(\% 60)\end{array}$ & $\begin{array}{l}15 \\
(\% 100)\end{array}$ & \\
\hline
\end{tabular}

Normal dağılıma uyan parametreler mean \pm SD şeklinde ifade edilmiştir. $p<0.05$ değeri anlamlı olarak kabul edilmiştir.

Tablo 2. JAK2 V617F mutasyonunun tanı gruplarına göre dağılımı

\begin{tabular}{|c|c|c|c|}
\hline \multirow{3}{*}{ Hastalık grupları } & \multicolumn{3}{|c|}{ JAK2 V617F Mutasyonu } \\
\hline & Var & Yok & Toplam \\
\hline & $n(\%)$ & $n(\%)$ & $n(\%)$ \\
\hline PV & $20(\% 8,5)$ & $215(\% 91,5)$ & $235(\% 100)$ \\
\hline ET & $3(\% 9,7)$ & $28(\% 90,3)$ & $31(\% 100)$ \\
\hline PMF & $0(\% 0)$ & $1(\% 100)$ & $1(\% 100)^{\prime}$ \\
\hline
\end{tabular}

ET: esansiyel trombositemi; PMF: primer miyelofibrozis; PV: polisitemia vera

Hastalar tanılarına göre 3 gruba ayrıldı. Her hastalık grubu kendi içerisinde JAK2 V617F mutasyonun pozitif ve negatif olma durumuna göre iki kategoriye ayrıldı. Tablo 2'de PV, ET ve PMF hasta gruplarında JAK2 V617F mu- 
tasyonun pozitif ve negatif oranları sayı ve yüzde olarak belirtildi. JAK2 V617F mutasyonun pozitifliği 235 PV hastasının $20(\% 8,5)$ 'sinde, $31 \mathrm{ET}$ hastasının $3(\% 9,7)$ 'ünde saptandı. PMF hasta grubunda 1 hasta yer almaktaydı ve JAK2 V617F mutasyonu gözlenmedi.

\section{Tartışma}

Kronik miyeloproliferatif hastalıklara genetik yatkınlık uzun zamandan beri bilinmekte ve hastalığa neden olan tanımlanmış genetik varyantlar bulunmaktadır. Bu hastalık grubunda sıklıkla tespit edilen JAK2V617F mutasyonunun klinik öneminin anlaşılmasından sonra Dünya Sağlık Örgütü tarafından 2008 yılında erişkin miyeloproliferatif malignite tanı ve sınıflama kriterleri içerisine dahil edilmiştir $(4,6)$.

Literatürde yer alan çalışmalarda JAK2 V617F mutasyonunun, PV'li hastaların yaklaşık \%90'nda, ET ve PMF'li hastaların yaklaşık \%50'sinde varlığı gösterilmiştir (7). Bizim çalışmamızda ise JAK2 V617F mutasyon pozitifliği PV hasta grubunun $\% 8,5^{\prime}$ inde, ET hasta grubunun $\% 9,7$ 'sinde saptandı. JAK2 V617F mutasyon görülme sıklı̆ının literatürde yer alan çalışmalardan farklı olarak ET tanılı hastalarda daha fazla olduğu gözlendi. Ayrıca çalışmamızda 1 PMF olgusunda JAK2 V617F mutasyonu negatif saptandı. Bu sonuç, JAK2 V617F mutasyon sıklığının toplumlara göre bölgesel farklılık gösterebileceğini ortaya koymaktadır. Ayrıca esansiyel trombositemi ve idiyopatik miyelofibrozisli hastaların sadece bir kısmında JAK2 V617F mutasyonunun gözlenmesi, bu hastalıkların genetik olarak heterojen olduğunu ortaya koymaktadır. Bu durum hastalığın moleküler temeli ve patogenezinin halen belirsizliğini korumasından kaynaklanmaktadır (8). Diğer taraftan kronik miyeloproliferatif hastalıkların alt tipleri için kesin tanısal kriterler olmasına rağmen, tam anlamıyla hastalığın sınıflandırılması halen tartışma konusudur. Ayırıcı tanıda hastalığı klinik olarak reaktif koşullardan, özellikle sekonder trombositoz ve eritrositozdan ayırt etmek zor olabilmektedir (7). Hastalığın ayıııcı tanısındaki güçlükler nedeniyle çalışmamızda JAK2 V617F mutasyon pozitifliğinin daha düşük oranlarda tespit edildiğini düşünüyoruz.

Miyeloproliferatif hastalıkların görülme sıklığı yaşla beraber artmakta olup ortalama yaş 60 'dır (9). Bizim çalışmamızda hastaların yaş ortalaması 42,07 $\pm 15,61$ idi. JAK2 V617F mutasyonu pozitif olan hastaların yaş ortalamasının ise daha yüksek olduğu gözlendi $(50,95 \pm 16,78)$. ÇaIışmamızda kadın ve erkek hastalar arasında JAK2 mutasyonu varlığı açısından anlamlı farklılık bulunmadı. Literatürde de yapılan çalışmalarda çalışmamızdaki bulgulara benzer şekilde cinsiyet ile JAK2 V617F mutasyonu arasında bir ilişki bulunmadığı belirtilmiştir (10).

Literatürde yer alan iki ayrı çalışmada, Yahudilerde miyeloproliferatif hastalıkların görülme oranının diğer popülasyonlara göre daha yüksek olduğu ve hastalık için risk faktörü olarak tanımlandığı vurgulanmıştır. Najean ve ark. tarafından yapılan çalışmada, PV vakalarının Fransa referans popülasyonundaki \% 3 orana kıyasla \% 5.8'inin Yahudi kökenli olduğu gösterilmiştir (11). Bununla birlikte Chaiter ve ark. tarafindan Kuzey İsrail'deki miyeloproliferatif hastalık tanılı olguların referans popülasyondaki \% 32.5'e karşılık \% 81.2'sinin Aşkenazi Yahudisi olduğu bildirilmiştir (12). Çalışmamızda ise JAK2 V617F mutasyonu pozitifliği kökenlere göre karşılaştırılığında Suriye'li hastalarda Türk hastalara kıyasla anlamlı olarak daha yüksek olduğu gözlendi $(p<0.05)$. Bu durum kökenlere göre JAK2 V617F mutasyon sıklığının değişebileceğini ortaya koymaktadır.

Schnittger ve ark. tarafından PV tanısı veya nedeni belirlenemeyen eritrositozu bulunan ve JAK2 V617F mutasyonu negatif saptanan 409 hastada JAK2 ekzon 12 mutasyonu ile ilişkisinin araştıııldığı bir çalışmada JAK2 geninin 12. eksonunda 4'ü daha önce tanımlanmamış olmak üzere (H538-K539del, E544-L545del, H538DK539LI540S, V536-F547dup) 9 farklı mutasyon saptanmıştır. JAK2 ekson 12 mutasyonunun pozitif olduğu hastalarda genellikle eritroid seri artışı diğer serilere göre daha baskın olduğu, eritropoetin düzeyinin daha düşük olduğu tespit edilmiştir. Sonuç olarak bu çalışmada JAK2 ekzon 12 mutasyon analizinin, PV veya eritrositozda tanı koymada katkısının olduğu bildirilmiştir (13). ÇaIışmamızda JAK2 V617F mutasyonu negatif hastalarda JAK2 ekson 12 mutasyon analizi yapılarak sonuçların değerlendirilmesinin ayrıca faydalı olacağını düşünmekteyiz.

Sonuç olarak, çalışmamızda JAK2 V617F mutasyon pozitifliği Suriye'li hastalarda anlamlı olarak daha yüksek olduğu gözlendi. Ayrıca çalışmamızda diğer çalışmalara göre JAK2 V617F mutasyon sıklığı daha nadir olduğu görüldü. JAK2 V617F mutasyonu ve JAK2 ekson 12 mutasyon analizi açısından daha fazla sayıda hastanın yer aldığı kapsamlı ve prospektif çalışmaların yapılması gerektiğini düşünmekteyiz. Ayrıca bölgemizde bu konuda yapılan ilk çalışma olması nedeniyle, bulgularımızın literatüre katkı sağlaması açısından önem arz edeceği kanaatindeyiz.

Çıkar Çatışması: Yazarlar konuyla ve/veya herhangi başka bir yazar ile ilgili maddi veya manevi bir çıkar ilişkisi içinde değillerdir.

\section{Kaynaklar}

1. Michiels JJ, Berneman Z, Schroyens W, De Raeve H. Changing concepts of diagnostic criteria of myeloproliferative disorders and the molecular etiology and classification of myeloproliferative neoplasms: from Dameshek 1950 to Vainchenker 2005 and beyond. Acta haematologica. 2015;133(1):36-51.

2. Arber DA, Orazi A, Hasserjian R, Thiele J, Borowitz MJ, Le Beau MM, et al. The 2016 revision to the World Health Organization classification of myeloid neoplasms and acute leukemia. Blood. 2016;127(20):2391-405. 
3. Baxter EJ, Scott LM, Campbell PJ, East C, Fourouclas N, Swanton $\mathrm{S}$, et al. Acquired mutation of the tyrosine kinase JAK2 in human myeloproliferative disorders. The Lancet. 2005;365(9464):1054-61.

4. Kaushansky K. The chronic myeloproliferative disorders and mutation of JAK2: Dameshek's 54 year old speculation comes of age. Best Practice \& Research Clinical Haematology. 2007;20(1):5-12.

5. Jones AV, Chase A, Silver RT, Oscier D, Zoi K, Wang YL, et al. JAK2 haplotype is a major risk factor for the development of myeloproliferative neoplasms. Nature genetics. 2009;41(4):446.

6. Wadleigh M, Tefferi A. Classification and diagnosis of myeloproliferative neoplasms according to the 2008 World Health Organization criteria. International journal of hematology. 2010;91(2):174-9.

7. Jones AV, Kreil S, Zoi K, Waghorn K, Curtis C, Zhang L, et al. Widespread occurrence of the JAK2 V617F mutation in chronic myeloproliferative disorders. Blood. 2005;106(6):2162-8.

8. Kralovics R, Skoda RC. Molecular pathogenesis of Philadelphia chromosome negative myeloproliferative disorders. Blood reviews. 2005;19(1):1-13.

9. Maffioli M, Orlandi E, Passamonti F. Chronic myeloproliferative neoplasms in the elderly. European journal of internal medicine. 2018;58:33-42.

10. Tefferi A, Lasho TL, Schwager SM, Strand JS, Elliott M, Mesa R, et al. The clinical phenotype of wild-type, heterozygous, and homozygous JAK2V617F in polycythemia vera. Cancer: Interdisciplinary International Journal of the American Cancer Society. 2006;106(3):631-5.

11. Najean $\mathrm{Y}$, Rain J, Billotey C. Epidemiological data in polycythaemia vera: a study of 842 cases. Hematology and cell therapy. 1998;40(4):159-65.

12. Chaiter $Y$, Brenner B, Aghai E, Tatarsky I. High incidence of myeloproliferative disorders in Ashkenazi Jews in northern Israel. Leukemia \& lymphoma. 1992;7(3):251-5.

13. Schnittger S, Bacher U, Haferlach C, Geer T, Müller P, Mittermüller $\mathrm{J}$, et al. Detection of JAK2 exon 12 mutations in 15 patients with JAK2V617F negative polycythemia vera. haematologica. 2009;94(3):414-8. 